Thorax, 1979, 34, 117-119

\title{
Dilatation of the azygos vein simulating a mediastinal tumour
}

\author{
J A SIDDORN AND L WORSORNU \\ From the Department of Medicine and Surgery, School of Medicine, University of Zambia, \\ Lusaka, Zambia
}

\begin{abstract}
A mediastinal tumour was simulated by gross dilatation of the azygos vein resulting from compression by enlarged hilar lymph nodes at the point where it crossed the right main bronchus to enter the superior vena cava. This cause of dilatation of the azygos vein has not previously been reported.

Published reports are reviewed and attention drawn to the large proportion of patients $(11 / 19)$ with this condition who had needless thoracotomies. The possibility of making a diagnosis by means of clinical observation and simple radiological techniques and thus avoiding surgical intervention is discussed.
\end{abstract}

Dilatation of the azygos and hemiazygos veins producing abnormal mediastinal or, less often, paraspinal shadows on chest radiographs is well documented and has been reported in portal hypertension with collateral circulation (Leigh et al, 1954; Campbell and Baruch, 1960; Blendis et $a l, 1968)$ and congenital and acquired abnormalities of both superior and inferior caval systems (Shuford and Weens, 1958; Bogedain and Carpathios, 1962; Steinberg, 1962; Petersen, 1965; Castellino et al, 1968; Floyd and Nelson, 1976) or it may be idiopathic (Sayer et al, 1954; Schmidt, 1954; Magbitang et al, 1960; Hoffman et al, 1961; Stern and Bloomberg, 1961; Walker, 1963). This dilatation, however, is not usually great, and as it is often accompanied by clinical or radiological evidence of the underlying condition it rarely creates a diagnostic problem. We report a case in which gross distension of the azygos vein from compression of this vessel centrally by lymph nodes secondary to a chronic lung abscess presented as a large radiological opacity in the posterior mediastinum and posed considerable diagnostic problems.

\section{Case report}

A middle-aged Zambian man attended the University Teaching Hospital, Lusaka, with a threemonth history of cough and chest pain. Initially he had purulent sputum but later haemoptysis occurred with increasing frequency. Pleuritic pain had been present on the right side throughout his illness, and shortly before admission to hospital he developed a constant dull gnawing pain deep to the supra-spinatus muscle.

He was thin, wasted, and appeared chronically ill, but the only abnormal clinical finding was a right-sided pleural effusion. In particular there was no engorgement of the neck veins, dependent oedema, varicosities of the legs, distension of superficial collateral veins, palpable liver or spleen, or evidence of hepatic disease. The chest radiograph (figs 1 and 2) showed a large spherical shadow with clear-cut margins in the posterior part of the right upper zone and another similar but more central opacity extending to the right of the midline in the lower zone. There was also some widening of the superior mediastinum and a small right pleural effusion. Apart from a raised erythrocyte sedimentation rate (60 mm/hour Westergren) results from all investigations including bronchoscopy and repeated examination of the sputum for malignant cells and acid- and alcohol-fast bacilli were normal. Further investigation with available techniques was considered unlikely to result in a definite diagnosis and a thoracotomy was carried out 12 days after admission.

At operation the mass in the posterior superior mediastinum was identified as an aneurysmal dilatation of the arch of the azygos vein that measured $8 \times 6 \mathrm{~cm}$. The dilatation was entirely confined to the arch and caused by enlarged hilar lymph nodes 


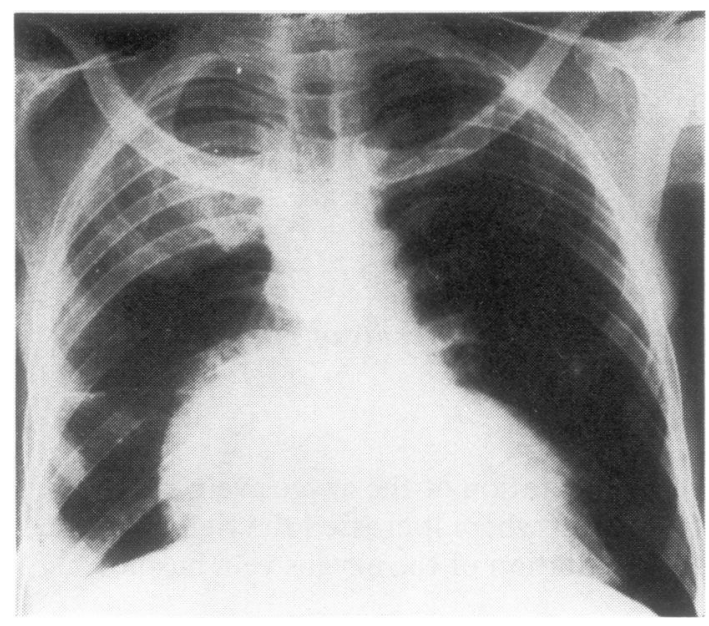

Fig 1 Posteroanterior chest radiograph showing superior and lower mediastinal shadows.

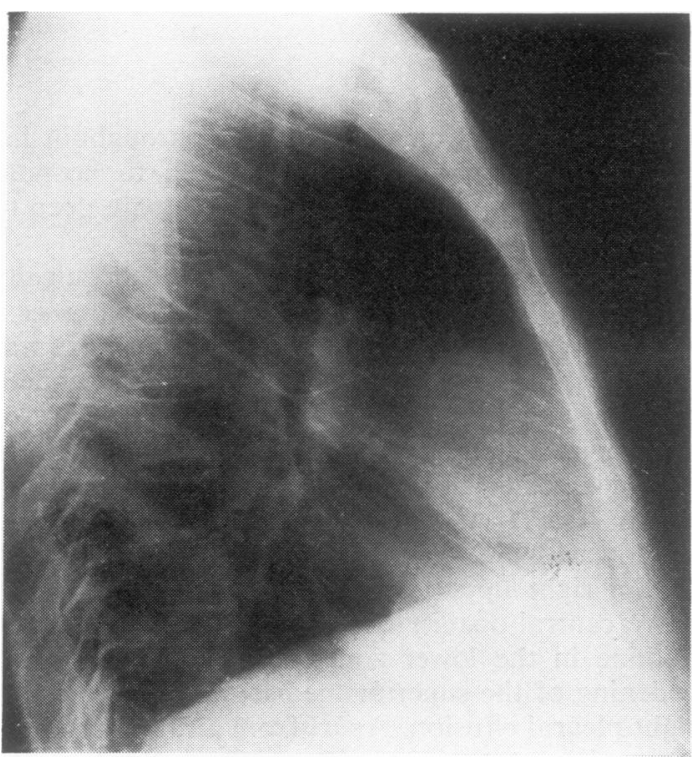

Fig 2 Lateral radiograph of same patient.

compressing the vein where it crossed the right main bronchus to enter the superior vena cava. The primary disease was a firm $12 \times 10 \mathrm{~cm}$ mass in the middle lobe, which together with the hilar lymphadenopathy suggested a malignancy necessitating pneumonectomy. Five days later the patient collapsed and died suddenly, apparently from a bronchopleural fistula.

The mass in the middle lobe was reported as a chronic lung abscess, and no evidence of malig- nancy was found in the surgical specimen. Permission for necropsy was withheld.

\section{Discussion}

Dilatation of the azygos or hemiazygos vein sufficient to simulate a tumour may be idiopathic or may occur in various conditions that produce either greater flow due to involvement of these veins in a collateral system or greater tension secondary to an increase in pressure in the superior vena cava. In this case the dilatation was due to a local obstruction. This has not been previously reported and as will be emphasised later has important diagnostic significance.

Nineteen cases of dilated azygos or hemiazygos veins simulating tumours have been traced (see table), and of these seven were associated with abnormalities of the inferior vena cava, three with lesions of the superior vena cava, and three with portal hypertension. No cause was found in six.

Table Causes of 12 cases of azygos vein dilatation with numbers in which clinical or radiological evidence for diagnosis was present and numbers of diagnostic thoracotomies performed

\begin{tabular}{lllll}
\hline Evidence present & No & Clinical & Radiological $\begin{array}{l}\text { Diagnostic } \\
\text { thoracotomy }\end{array}$ \\
\hline $\begin{array}{l}\text { Obstruction of inferior } \\
\text { vena cava }\end{array}$ & 7 & $4^{*}$ & $4^{*}$ & 3 \\
$\begin{array}{l}\text { Obstruction of superior } \\
\text { vena cava }\end{array}$ & 3 & 3 & $2^{*}$ & 1 \\
$\begin{array}{l}\text { Portal hypertension } \\
\text { Idiopathic }\end{array}$ & 3 & 3 & 3 & 1 \\
\hline
\end{tabular}

*Insufficient data given for one case.

$\dagger$ Insufficient data given for two cases.

Awareness of the appearances of the dilated azygos vein will often allow it to be recognised with little difficulty and without sophisticated techniques, since clinical evidence of caval obstruction, portal hypertension, or collateral circulation may be seen. This evidence was present in most published cases where clinical details were given (see table). The radiological criteria listed by Fleischner and Udis (1952) to enable azygos and hemiazygos aneurysms to be distinguished from tumours are useful in differentiating between the two entities. The importance of this basic clinical and radiological information cannot be over-emphasised as many of the 11 thoracotomies in cases previously reported could have been avoided if the significance of available information had been realised.

In the reported case no clinical evidence was present as the dilatation was produced by a purely 
local obstruction, and the magnitude of the aneurysm $(8 \times 6 \mathrm{~cm})$ invalidated the criteria of Fleischner and Udis (1952), thus emphasising that the diagnosis is not always indicated clinically or radiologically. At present the most reliable method of consistently demonstrating this condition is intraosseous azygography (Schwartz et al, 1959). It is suggested that in mediastinal lesions in which a diagnosis cannot be made this investigation should be performed before a thoracotomy is undertaken.

\section{References}

Blendis, L M, Laws, J W, Williams, R, and Thomson, W B (1968). Calcified collateral veins and gross dilatation of the azygos vein in cirrhosis. British Journal of Radiology, 41, 909-912.

Bogedain, W, and Carpathios, J (1962). Dilated azygos vein simulating mediastinal tumor. Postgraduate Medicine, 31, 490-491.

Campbell, H E, and Baruch, R J (1960). Aneurysm of the hemiazygos vein associated with portal hypertension. American Journal of Roentgenology, 83, 1024-1026.

Castellino, R A, Blank, N, and Adams, D F (1968). Dilated azygos and hemiazygos veins presenting as paravertebral intrathoracic masses. New England Journal of Medicine, 278, 1087-1091.

Fleischner, F G, and Udis, S W (1952). Dilatation of azygos vein. Radiological signs of venous engorgement. American Journal of Radiology, 67, 569-575.

Floyd, G D, and Nelson, W P (1976). Developmental interruption of the inferior vena cava with azygos and hemiazygos substitution. Usual radiographic features. Radiology, 119, 55-57.
Hoffman, G H, Larson, V O, Shipman, G A, and Sparger, C (1961). Venous anomaly of hemiazygos system. Radiology, 77, 626-628.

Leigh, T F, Abbott, O A, Rogers, J V, and Gay, B B (1954). Venous aneurysms of the mediastinum. Radiology, 63, 696-705.

Magbitang, $M$ H, Hayford, F $\mathrm{C}$, and Blake, J M (1960). Dilated azygos vein simulating a mediastinal tumor. New England Journal of Medicine, 263, 598-600.

Petersen, R W (1965). Infrahepatic interruption of the inferior vena cava with azygos continuation. Radiology, 84, 304-307.

Sayer, W J, Parmley, L F, and Morris, J del S (1954). Mediastinal tumor simulated by azygos phlebectasia. Annals of Internal Medicine, 40, 175-182.

Schmidt, W R (1954). Dilatation of major azygos vein simulating mediastinal tumor. Journal of Thoracic Surgery, 27, 251-254.

Schwartz, S, Handel, J, and Candel, S (1959). Azygography. Radiology, 72, 338-343.

Shuford, W H, and Weens, H S (1958). Azygos vein dilatation simulating mediastinal tumor. American Journal of Roentgenology, 80, 225-230.

Steinberg, I (1962). Dilatation of hemiazygos veins in superior vena caval occlusion obstruction simulating mediastinal tumor. American Journal of Roentgenology, 87, 248-257.

Stern, W Z, and Bloomberg, A E (1961). Idiopathic azygos phlebectasia simulating mediastinal tumor. Radiology, 77, 622-625.

Walker, A W (1963). Aneurysm of the azygos vein, aetiology undetermined. American Journal of Roentgenology, 90, 575-577.

Requests for reprints to: Dr J A Siddorn, 11 Brownlees Road, Biddulph, Stoke-on-Trent ST8 6PJ. 